7-15-2021

\title{
Beyond Degrees: The Kalamazoo Promise and Workforce
}

\section{Outcomes}

Isabel McMullen

W.E. Upjohn Institute for Employment Research, mcmullen@upjohn.org

Brad J. Hershbein

W.E Upjohn Institute for Employment Research, hershbein@upjohn.org

Upjohn Author(s) ORCID Identifier:

(iD) https://orcid.org/0000-0002-1831-7175

(D) https://orcid.org/0000-0002-2534-8164

Follow this and additional works at: https://research.upjohn.org/up_policybriefs

Part of the Labor Economics Commons

\section{Citation}

McMullen, Isabel and Brad J. Hershbein. 2021. "Beyond Degrees: The Kalamazoo Promise and Workforce Outcomes." Policy and Research Brief. Kalamazoo, MI: W.E. Upjohn Institute for Employment Research. https://doi.org/10.17848/pb2021-37 


\section{Beyond Degrees: The Kalamazoo Promise and Workforce Outcomes}

\section{Isabel McMullen and Brad Hershbein}

\section{BRIEF HIGHLIGHTS}

Tuition-free programs like the Kalamazoo Promise have potential to improve workforce outcomes, but they will be more effective with deliberate efforts to match degree-earners with local employers.

We find the Kalamazoo Promise did not meaningfully increase instate employment among scholars seven to nine years after high school graduation.

The scholarship did, however, slightly increase average earnings and modestly increased the chance that recipients earned at least $\$ 25,000$ a year.

- Recipients of the scholarship were also more likely to live near Kalamazoo's central business district.

For additional details, see the working paper at https://research.upjohn.org/up workingpapers/350/.
$\mathrm{T}$ uition-free college scholarships based on residency, often called Promise or placebased programs, are still a relatively new addition to the policy landscape. While many college scholarships frame eligibility around need or merit, place-based programs provide college funding based on where an individual lives, often a municipality or school district. The goal is not only to support individual students, but also to create better job opportunities and help revitalize the local economy. While approximately 200 such programs now exist nationwide, few have been around long enough to understand their impacts on college completion, let alone on workforce outcomes after college. Thus, the extent to which place-based policies of this kind can achieve their economic goals remains an open question.

Having operated for more than 15 years, the Kalamazoo Promise has yielded compelling results in terms of postsecondary access and attainment. Scholars eligible for the Promise receive first-dollar funding-before other aid is counted-to attend any public two- or four-year institution in the state of Michigan, and are eligible for funding up to 130 credits, a bachelor's degree, or 10 years (whichever comes first). ${ }^{1}$ In part because of this flexibility and generosity, previous research found the Promise led to a 14 percent increase in immediate college enrollment and a 28 percent increase in the likelihood of earning a postsecondary credential by six years after high school (Bartik, Hershbein, and Lachowska 2020). To understand how these gains in college access and completion have in turn affected alumni's workforce success, we and our coauthors obtained employment and earnings data from the State of Michigan's Unemployment Insurance program on graduates of Kalamazoo Public Schools. We compared outcomes among Promise eligible and ineligible graduates, before and after the scholarship was implemented, to estimate the effect of the Promise on key labor market outcomes: employment (in Michigan), earnings, and proximity of residence to Kalamazoo.

We find that the Promise had no meaningful impact on recipients' employment in Michigan within the first decade after high school graduation. However, there is some evidence that the Promise boosted average earnings by about 6 percent, and stronger evidence that it increased the likelihood that scholars earn upwards of $\$ 25,000$ to $\$ 40,000$ by their mid-to-late 20s. Moreover, because of the Promise, alumni also became more likely to live within 20 miles of Kalamazoo's central business district.

These findings demonstrate that place-based college scholarships have potential to spur workforce development, but that even the most generous of them are not panaceas. As programs like the Kalamazoo Promise age and new programs emerge, including more wide-scale tuition-free scholarships, our study is an important reminder that degrees alone will not necessarily produce higher employment or better jobs, and that workforce and economic development programs must work simultaneously to grow the local economy.

${ }^{1}$ These features were in effect during the time period of our analysis. As of this writing, students may also use the Promise to attend most private colleges and universities in Michigan, and the credit cap has been raised to 145 credits. 
We use data from the

Michigan Unemployment

Insurance (UI) Agency

matched to individuals

in the KPS education

records.

\section{The Kalamazoo Promise, Workforce Data, and Our Approach}

Since the inaugural class of 2006, the Kalamazoo Promise has distributed funding to over 6,000 students from the Kalamazoo Public Schools (KPS), of which more than 2,300 have earned a postsecondary credential. To be eligible, students must attend (and reside in) the KPS district from at least ninth grade, but there are no other financial need or merit requirements. Consequently, about 90 percent of KPS high school graduates are eligible for Promise funding (W.E. Upjohn Institute 2021). The KPS school district partners closely with the Kalamazoo Promise to provide data on scholarship eligibility, and the district also discloses other demographic, residency, and achievement variables to the Promise. We draw on these data, which predate the Promise, to conduct our analysis.

For outcomes, we use data from the Michigan Unemployment Insurance (UI) Agency matched to individuals in the KPS education records. The Michigan UI data contain quarterly earnings for all individuals working in a UI-covered job in Michigan. This includes most forms of employment; however, it excludes federal government workers, those who are self-employed, and anyone working in a freelance or gig-style job. Additionally, anyone working outside of the state is also excluded, so we are unable to observe those who have left Michigan. Overall, we match 79 percent of all KPS graduates from the classes of 2003-2013 to at least one UI record. For those matched, we observe their quarterly earnings at each job from 2006 through the beginning of 2019, as well as their ZIP code of residence each quarter.

Note that even individuals who match do not necessarily have an earnings record every quarter. In most cases, a missing quarter implies no employment, and we generally treat it as such, although we cannot rule out the noncovered employment activities mentioned above. These issues are likely to arise in any analysis of an education program that relies on similar state UI data. In the full paper, we discuss how unmatched individuals (and unmatched quarters) are likely to affect our analyses, and we explore the sensitivity of our results to different assumptions, but our core findings are unaffected.

Our primary approach to understand the effects of the Kalamazoo Promise on the workforce outcomes of scholarship recipients compares differences between eligible and ineligible students before and after the scholarship was implemented in 2006. Our main outcomes of interest include: 1) employment status (which we define as whether an individual had earnings in three or four quarters of a four-quarter period); 2) inflationadjusted quarterly earnings averaged over a four-quarter period; 3 ) whether these earnings exceeded various thresholds; and 4) whether an individual lived within certain distances from Kalamazoo's central business district. Although we estimate impacts at different time horizons since high school graduation, we focus on the period when individuals are in their mid-to-late 20s, and most have finished their schooling and begun their careers.

\section{Results}

We find that the Kalamazoo Promise has had minimal effects on employment, whether measured as working at least three or all fours quarters in a four-quarter period. This suggests that the Promise's positive impact on degree and credential attainment does not translate into a greater propensity for scholars to work within Michigan in early career. Although it is possible employment impacts may surface later in the career, this finding could also occur if the degree impacts more greatly affect the types of jobs that scholars take, rather than whether they have a job at all.

Thus, we also examine effects on average quarterly earnings, as shown in Figure 1. The left panel indicates that Promise recipients had somewhat higher quarterly earnings 7-10 after high school graduation, but the overall levels are quite low because all quarters without earnings are treated as zeros in the comparison. This graph thus captures Promise impacts on both employment and earnings. The panel on the right focuses on 
The Promise slightly

increased the likelihood

of earning at least $\$ 6,000$

per quarter $(\$ 24,000$

annualized) by the time

scholars were in their

mid-to-late 20s. Figure 1 The Kalamazoo Promise Only Slightly Increased Average Quarterly
Earnings 7-10 Years after High School Graduation

$\begin{array}{rrr} & \text { All individuals } & \$ 8,000 \\ \$ 4,000 & & \\ \$ 3,500 & \text { Promise } & \$ 7,000 \\ \$ 3,000 & \$ 6,000 \\ \$ 2,500 & \text { Control } & \$ 5,000 \\ \$ 2,000 & \$ 4,000 \\ \$ 1,500 & \$ 3,000 \\ \$ 1,000 & \$ 2,000 \\ \$ 500 & \$ 1,000 \\ \$ 0 & \$ 0\end{array}$

Employed individuals

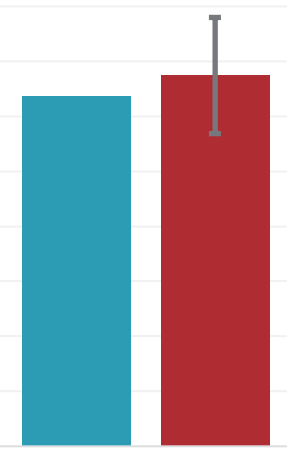

NOTE: The dependent variable is the inflation-adjusted average quarterly earnings (in 2018 dollars) of an individual over the specified time frame. The bar for the Promise group is constructed by adding the estimated Promise effect to the control group mean, and the whiskers show 95-percent confidence intervals. The left panel uses a sample that treats missing person-quarters as implicit zeros, while the right panel uses a sample that includes only matched person-quarters with positive earnings.

SOURCE: Authors' calculations from KPS and Michigan UI administrative data.

employed individuals, counting only quarters with positive earnings. Promise-eligible individuals on average earn $\$ 6,743$ per quarter, about $\$ 390$, or 6 percent, more than the control group. However, neither of these effects is statistically significant, so these results are only suggestive.

Of course, earnings vary considerably across individuals, especially early-career earnings, and even if the Promise had only minor effects on average earnings, it may have had larger impacts in lifting earnings at the bottom. Figure 2 shows how the Kalamazoo Promise affected the likelihood of having quarterly earnings of at least the amounts shown in the horizontal axis. Among all individuals, not just the employed, the Promise increased the likelihood of earning at least $\$ 6,000$ per quarter ( $\$ 24,000$ annualized) by the time scholars were in their mid-to-late 20 s. This boost occurred up to about $\$ 10,000$ per quarter, implying eligible individuals also had increased chances of earning at least $\$ 40,000$ on an annualized basis. Among those employed (not shown in the figure), the Promise increased the chances of earning at least $\$ 7,000$ per quarter-enough to exceed the poverty threshold for a family of four-from 73 percent to 78 percent, a small but meaningful increase. Thus, we find somewhat stronger evidence that the overall earnings distribution was shifted up by the Promise.

The strongest effects we find are for the likelihood of living close to central Kalamazoo. In particular, by their mid-to-late 20s, Promise-eligible graduates were 11-12 percentage points more likely to live within 10 or 20 miles of the city center, roughly corresponding to the outer edges of the metro area. These impacts indicate the Promise has had some success in keeping high school graduates close by, even after much of their schooling is complete.

\section{Discussion and Implications}

Despite the large increases in educational attainment the Promise induced (Bartik, Hershbein, and Lachowska 2020), we find that these educational gains have not translated into clear and convincing gains in employment and earnings. Although there is some evidence for earnings improvement in the middle of the distribution, and for greater geographic retention of individuals, impacts are generally modest. We think there are at least two reasons for the somewhat lackluster findings. First, even a horizon 
By their mid-to-late

20s, Promise-eligible

graduates who remained

in state were 11-12

percentage points more

likely to live within 20

miles of Kalamazoo.
Figure 2 The Kalamazoo Promise Increased The Chances of Earning At Least \$6,000 Per Quarter, 7-10 Years after High School Graduation

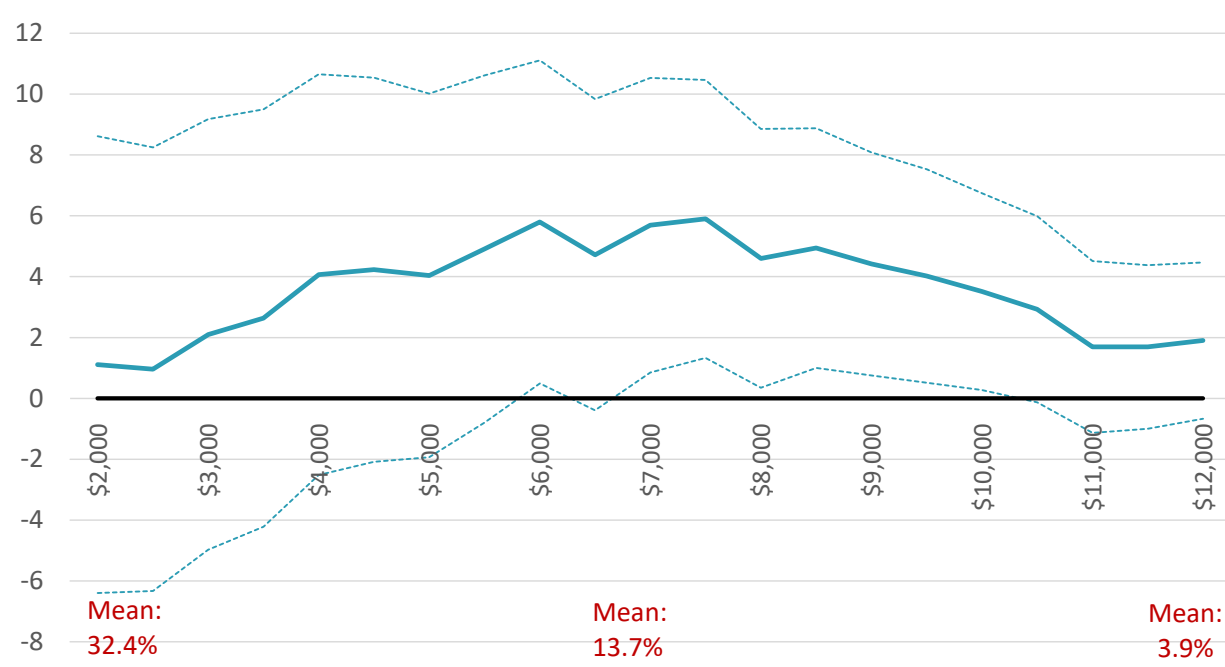

NOTE: The dependent variables are whether the individual's average quarterly earnings (counting quarters of zero earnings) exceed the inflation-adjusted amounts shown in the horizontal axis. The solid blue line shows the Promise effect, in percentage points, on the probability of exceeding these thresholds. Select mean probabilities for the control group are shown in red at the bottom. For example, just under 14 percent of control individuals earned $\$ 7,000$ or more per quarter, but about 20 percent of Promise-eligible individuals did. The dashed blue lines show 95 percent confidence intervals.

SOURCE: Authors' calculations from KPS and Michigan UI administrative data.

\section{Figure 3 The Kalamazoo Promise Increased the Chances of Living Closer to Kalamazoo 7-10 years after High School Graduation}

$120 \%$

$100 \%$

$80 \%$

$60 \%$

$40 \%$

$20 \%$

$0 \%$

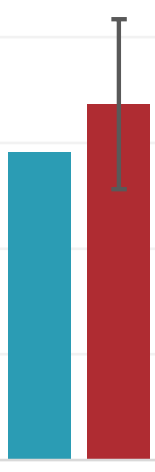

$\leq 5$ miles
Control $\quad$ Promise

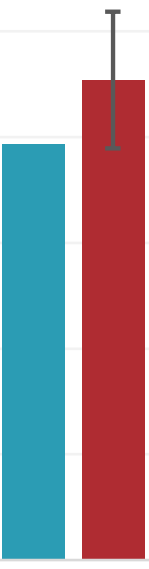

$\leq 10$ miles

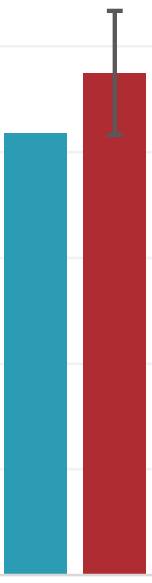

$\leq 20$ miles

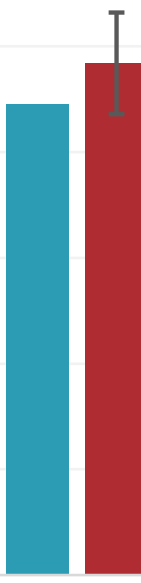

$\leq 50$ miles
NOTE: The dependent variable is an indicator for whether the centroid of the individual's ZIP code is within the specified distance of Kalamazoo's central business district, ZIP code 49007. The bar for the Promise group is constructed by adding the estimated Promise effect to the control group mean, and the whiskers show 95 percent confidence intervals.

SOURCE: Authors' calculations from KPS and Michigan UI administrative data. 


\section{If local job opportunities are lacking, place-based college scholarships could lead to increased educational attainment but not improved employment and earnings.}

of 7-10 years after high school may be too soon for full effects to emerge, especially if lingering impacts of the Great Recession slowed career advancement. Second, the context of Kalamazoo's labor market may be a factor. Compared to growing areas like Knoxville, Tennessee, which saw stronger employment and earnings effects from the place-based scholarship that grew into the Tennessee Promise (Carruthers, Fox, and Jepsen 2020), the Kalamazoo area (and Michigan more generally) has seen little job or population growth in recent years. Consequently, there may have been fewer job opportunities for Promise grads, causing some to lack employment and others to leave the state.

If local job opportunities are lacking, it is possible that place-based college scholarships could very well lead to increased educational attainment but not improved employment and earnings. As more states adopt explicit education goals to reach a certain share of their working-age population with post-secondary education credentials, our results serve as a cautionary reminder that greater educational attainment by itself may not be sufficient to lead to better workforce outcomes. Additional measures to promote job development may be necessary, including greater cooperation with other community stakeholders, economic development entities, and the business community.

Note: The research for this project was conducted under the auspices of Michigan Works! Southwest, the employment services agency for four counties in southwest Michigan and covering the Kalamazoo Public Schools. The authors thank Ben Damerow, the director of Michigan Works! Southwest, for his assistance and support of the research.

\section{References}

Bartik, Timothy J., Brad J. Hershbein, and Marta Lachowska. 2020. “The Effects of the Kalamazoo Promise Scholarship on College Enrollment and Completion.” Journal of Human Resources 56(1): 269-310. DOI: https://doi.org/10.3368/jhr.56.1.0416-7824R4.

Carruthers, Celeste K. and William F. Fox, and Christopher Jepsen. 2020. "Promise Kept? Free Community College, Attainment, and Earnings in Tennessee." University of Tennessee working paper.

W.E. Upjohn Institute for Employment Research. 2021. Kalamazoo Promise: Data Collection. Kalamazoo, MI: W.E. Upjohn Institute for Employment Research. https://www. upjohn.org/about/research-initiatives/promise-investing-community/kalamazoo-promisedata-collection
W.E. Upjohn Institute for Employment Research 